\title{
Impact of Taiwan open policy on Chinese tourist satisfaction
}

\author{
Shuang Cang ${ }^{\mathrm{a}} *$, Ya-Yen $\mathrm{Sun}^{\mathrm{b}}$ and $\mathrm{ShiNa} \mathrm{Li}^{\mathrm{c}}$ \\ a: School of Tourism, Bournemouth University, Fern Barrow, Poole, Dorset BH12 5BB, UK \\ b: Department of Transportation \& Communication Management Science, National Cheng Kung University, No. 1, \\ University Road, Tainan City 70101, Taiwan, R.O.C. \\ c: School of Events, Tourism and Hospitality, Leeds Beckett University, Leeds LS6 3QN, UK
}

\begin{abstract}
The Taiwan government has imposed a daily visitation quota with strict regulations on Chinese visitor travel modes, length of stay, and visa authorizations since July 2008. This highly controlled scheme was an attempt to maintain service quality on top of security and political considerations. The purpose of this study is to provide in-depth analysis regarding the Chinese tourist satisfaction over time under different travel modes. The results indicated that package tour (PT) visitors generally gave higher satisfaction scores than free and independent travel (FIT) visitors. However, PT visitors demonstrated a decreased level of satisfaction on their tour arrangements of hotels, meals, itineraries. Addressing safety and environmental issues is the priority task in order to provide quality travel services.
\end{abstract}

Keywords: Tourist satisfaction; Policy impact; Travel mode; Package Tour; Free and independent travel

\section{Introduction}

Due to rapid urbanization, rising disposable incomes, and government support for foreign travel, the outbound tourism volume from China has grown vigorously. This strong demand for outbound travel started in 2000 with an annual average growth rate of $22.0 \%$, and expenditures on outbound travel has expanded four times in the past decade (World Tourism Organization, 2011; World Tourism Organization and European Travel Commission, 2008 ). This phenomenon has exceeded the previous $\mathrm{UNWTO}^{1}$ forecast, and China has overtaken, respectively, Italy, Japan, France, and the United Kingdom, as the 3rd largest source market, with total expenditures of 54.9 billion in 2010, only after Germany and the United States. On 2009, Chinese Premier Wen Jiabao further endorsed the "Statement on Accelerating the Tourism Industry Development", which was the first time the expansion of outbound tourism was officially promoted. With the strong economic growth and a consistent policy of encouraging outbound tourism, it is estimated that China may become the largest source market worldwide for international travel by 2015 (Zhang, Song, \& Liu, 2010) . This trend of the strong growth in outbound tourism from China makes every country want to position themselves as a choice destination for the mainland Chinese population.

The qualified Chinese candidates for travel to Taiwan were differentiated into three groups, and the date each category was allowed to travel to Taiwan was listed, respectively, as:

- Type 1 visitor: Chinese nationals residing in mainland China (excluding Hong Kong or Macao residents). (18 July 2008)

- Type 2 visitor: Chinese nationals who arrive as part of an approved trip, routing through a third country before coming to Taiwan. (10 May 2002)

- Type 3 visitor: Chinese nationals who have permanent residency in a foreign country or who have worked in a foreign country for more than 4 years. (1 Jan. 2002)

Type 3 visitors are generally perceived as residents coming from countries outside of China, and type 2 visitors are associated with profiles as scientists, businessman, technology

\footnotetext{
${ }^{1}$ United National World Tourism Organization
} 
leaders, journalists, actors, scholars and athletes. Types 2 and 3 Chinese visitors only account for a very small number of the Chinese market share. The majority of Chinese nationals fall into the first category, type 1, and their travel privileges to Taiwan were only granted in 2008 based on a two-side governmental agreement between the "Straits Exchange Foundation" and the "Association for Relations Across the Taiwan Strait" . The milestone policy for Taiwan, the "Opening up to mainland Chinese Tourist Arrivals" policy, was inaugurated on July 18, 2008.

Preparatory measures for responding to an influx of tourists from mainland China were taken, and further restrictions on travel mode, length of stay, and the daily maximum quota in Taiwan were imposed (Table 1). At the beginning stage, package tours (PT), where group tours arranged through a travel agency or individual tours arranged through a travel agency, were the only travel modes allowed, which required Chinese tourists to enter and exit Taiwan using a pre-approved itinerary (Lin \& Lin, 2006). The PT regulation was later relaxed in January 2011 by allowing the visit to be on the Free and Independent Travel (FIT) format. These types of travel refer to those trips with 1) accommodations arranged or airline tickets booked through a travel agency, 2) self-guided tours, with part of their itinerary and activities arranged by a Taiwan travel agency after arrival, and 3) self-guided tours without any arrangements by a Taiwan travel agency after arrival. The initial daily quota for FIT tourists was 500 people, which was later raised to 1,000 people on April 2012. The transition from the PT travel format to FIT represents the Taiwanese government taking precautionary measures toward this segment until they are proven to incur the least extent of illegal stay and crime activities.

Table 1: Travel regulations for Type 1 China visitors to Taiwan

\begin{tabular}{lcccc}
\hline Date & Mode & $\begin{array}{c}\text { No. of people in a } \\
\text { package tour }\end{array}$ & $\begin{array}{c}\text { Max. length of } \\
\text { stay in Taiwan }\end{array}$ & $\begin{array}{c}\text { Daily quota } \\
\text { (people) }\end{array}$ \\
\hline \hline 18 July 2008 & PT only & $10 \sim 40$ & 10 & 3,000 \\
\hline 17 Jan 2009 & PT only & $5 \sim 40$ & 15 & 3,000 \\
\hline 1 Jan 2011 & PT only & $5 \sim 40$ & 15 & 4,000 \\
\hline 22 June 2011 & PT & $5 \sim 40$ & 15 & 4,000 \\
& FIT $^{1}$ & & 15 & 500 \\
\hline 28 Apr 2012 & PT & $5 \sim 40$ & 15 & 4,000 \\
& FIT $^{2}$ & & 15 & 1,000 \\
\hline
\end{tabular}

T. Only residents of Bejing, Shanghai, and Xiamen are allowed.

2. Residents from additional 10 cities are allowed. Source: (National Immigration Agency, 2012a; Taiwan Tourism Bureau, 2012a).

Even with the control of the daily quota, visitation from mainland China has increased from 89,000 visits in 2008 to 1.30 million in 2011 , with an annual growth rate of $144 \%$. In the meantime, the Chinese market has surpassed Japan and became the largest inbound source market for Taiwan in 2011, accounting for $29 \%$ of the total annual international visitors that year (Taiwan Tourism Bureau, 2012b). The importance of this specific market and its contribution to Taiwan's economy is also well demonstrated through a Chinese high spending profile of US $\$ 234$ per visitor per day (only after Japanese tourists' US\$269 per visitor per day) and with an average length of stay of 7.6 nights, the longest stay among all inbound Asian visitors (Taiwan Tourism Bureau, 2010).

Given a highly controlled scheme with respect to Chinese visitors, their satisfaction under this circumstance reveals a picture more directly relating to the tourism capacity of local industries and to managerial procedures. Therefore, the purpose of this study is to provide an 
in-depth assessment regarding the satisfaction level of Chinese visitors to Taiwan before and after the opening policy. Results are used to provide implications regarding tourism capacity and visitation volume, given the strong growth trend toward Chinese outbound tourism.

\section{Literature review}

\section{Tourist Satisfaction}

Tourist satisfaction has become a crucial issue in the tourism industry. Satisfied tourists are inclined to show a higher level of loyalty through revisits, positive word of mouth and through their recommendation of destinations to friends and relatives, which can further increase tourist numbers, tourism expenditures and the economic growth of the destination (Akama \& Kieti, 2003; Söderlund, 1998). Also, understanding tourist satisfaction enables tourism organisations to improve tourism products and service quality and helps governments to formulate tourism policies (Yu \& Goulden, 2006).

Research on satisfaction consists of two key dimensions - the structure and the process (Singh, 1991). For the former dimension, the satisfaction structure relates to concepts. Oliver (1997) defined satisfaction as "a judgement that a product, or service feature, or the product or service itself, provides a pleasurable level of consumption-related fulfilment, including levels of under or over fulfilment' (p.13). The satisfaction process, on the other hand, refers to the causal relationships between satisfaction and other elements. An important antecedent element is expectations, which can positively influence tourist satisfaction, and a consequence element is customer loyalty, which can be positively affected by tourist satisfaction (Bosque, Martín, \& Collado, 2006).

There is no agreement on the determinant factors on consumer satisfaction. de Rojas and Camarero (2008) summarised two characteristics of the nature of satisfaction: cognitive and affective. According to the cognitive characteristic, the level of satisfaction can be measured by comparing the difference between tourist expectations before visiting and tourist perceived performance of the destination after a visit. This difference can be defined as nonconfirmatory experience, and this cognitive characteristic can be explained as an expectancy disconfirmatory paradigm, which is shared by most studies as a theoretical foundation (Millán \& Esteban, 2004; Wong \& Law, 2003). Tourists are satisfied if perceived performance exceeds or meet their expectations. Based on the affective characteristic, recent studies have argued that emotions are fundamental factors in the formation of tourist satisfaction, especially in the context of cultural tourism (de Rojas \& Camarero, 2008).

\section{Attributes Affecting Chinese Tourists' Satisfaction}

Because a tourism destination includes a basket of different services and products, it is necessary to measure satisfaction not only at the overall level but for each individual attribute (Li \& Carr, 2004; Yu \& Goulden, 2006). Different attributes may affect overall satisfaction equally, and some attributes may be more significant than others (Alegre \& Garau, 2010; Hui, Wan, \& Ho, 2007). The symmetric and asymmetric influences of destination attributes on overall visitor satisfaction (Albayrak \& Caber, 2013). One of the key attributes affecting tourists' satisfaction is service personnel performance (Huang, Hsu, \& Chan, 2010), which mainly refers to the performance of tour guides during package tours (Geva \& Goldman, 1991). Bowie and Chang (Bowie \& Chang, 2005) explored tourist satisfaction, especially targeting guided package tours. Their study identified that tour leaders' performance and their leadership skills can largely determine how satisfied a tourist can be. Especially, from Asian 
tourist perspectives, tour guides' service attitudes are more crucial than their service performance (Bowie \& Chang, 2005). Lee, Lee and Arcodia studied the effect of community attachment on visitors' satisfaction using cultural festival in Korea as an example (Lee, Lee \& Arcodia, 2013).

There have been many studies that have evaluated the satisfaction of outbound Chinese tourists with different destination attributes. Truong \& King (2009) explored Chinese tourists' satisfaction of destination attributes in Vietnam and discovered that Chinese tourists were most satisfied with natural scenery, tourism activities such as cruises and the quality and variety of restaurants, but among the most import attributes, tourists were least satisfied with Chinese spoken at their destinations, signs posted in attractions and the availability of brochures in their own language. This implies that Chinese tourists consider efficient and effective communication between tourists and the tourism destination as a key to their satisfaction. Kau and Lim (2005) categorised Chinese tourists to Singapore into four clusters and found that family travellers were the most satisfied group, while groups seeking knowledge and prestige were the least satisfied groups across various destination attributes. All four groups were highly satisfied with environmental attributes regarding cleanliness and security (Kau \& Lim, 2005). Qu and Li (1997) examined the characteristics and satisfaction of mainland Chinese tourists travelling to Hong Kong, and their results showed that mainland tourists were quite satisfied with all attributes apart from the prices charged. Tourist satisfaction has not only been studied from destination attributes but also by services provided by business sectors. Song, Li, Veen, and Chen (2011) compared the satisfaction levels of three sectors, including hotels, retail shops and tour operators, perceived by mainland Chinese individuals travelling to Hong Kong and found that Chinese tourists were most satisfied with the hotels but least satisfied with tour operators, which may indicate that there is room for the improvement of the tour operators in Hong Kong.

Research on tourism policy has focused on different areas, such as the role of government (e.g. Zhang, Chong and Ap, 1999), policies on sustainability (e.g. Griffin and Stacey), stakeholder issues (e.g. Pforr, 2006; Anastasiadou, 2008). The role of tourist satisfaction on destination development has been examined in the literature. Tourist dissatisfaction may cause the dissatisfaction of the overall destination (Pizman, Neuman, Reichel, 1979). Pavlic, Perucic and Portolan (2011) argued that tourist satisfaction plays important role in increasing tourism destination competitiveness. However, the research on how policy changes effects tourist satisfaction is rarely studied in the tourism literature, in particular, the satisfaction of mainland Chinese tourists to Taiwan. Lin and Lin (2006) assessed mainland Chinese tourists' satisfaction with a particular aspect of tourism, shopping in Taiwan, and revealed that Chinese tourists were most satisfied with "provision of home delivery service" but least satisfied with eight items such as "uniqueness of products" and "price of products" among twenty items regarding shopping.

This paper will be the first to examine the satisfaction level of mainland Chinese tourists to Taiwan with various destination attributes under the opening policy. This study is different from previous Chinese satisfaction studies because first, this market is under a highly controlled system regarding daily quotas, travel modes and visa approval, setting it apart from less intervened destinations. Secondly, this market has experienced a dramatic visitation growth, which placed stringent tests on the regional destinations involved. Due to these two factors, tourist satisfaction levels reveal a picture more directly related to tourism regulations, policies and capacity. 


\section{Methodologies}

\section{Dataset}

The dataset for visitor satisfaction, the annual visitor inbound survey, was provided by the Taiwan Tourism Bureau from the years 2007 to 2010. The survey was conducted monthly at two major international airports and sea ports before inbound visitors departed back to their point of origin or their next international destination. The annual sample size of the inbound visitor survey was around 5,000 in total, from which the sample size of the individual country was pre-determined in direct proportion to the previous year travel volume. Two versions (English and Chinese) of the questionnaire were designed, and the Chinese version was used for the mainland Chinese tourists. The questionnaire covered a variety of dimensions, but only satisfaction and demographics were adopted in our analysis. The first set of satisfaction questions in the survey addressed the package tour experiences, including attributes itinerary, accommodations, transportation, meals, tour guide service attitude, professionalism of the tour guide interpretations, and overall impressions; the second set of questions consisted of 15 items related to visitor experiences in Taiwan, differentiated by three major categories that included "convenience, environment, safety", and finally, overall satisfaction.

The convenience category includes questions on visa applications, immigration processes, transportation, and access to tourism information. Most of them are related to the pre-trip arrangements and the first impressions of the journey to Taiwan. Variables addressed in the survey included: efficiency of applying for a visa, international transportation to Taiwan (ease of obtaining tickets, flight times, etc.), local transportation, communication facilities (int'l public telephones, the Internet), access to tourism information, local transportation, immigration procedures, and customs procedures. The environment category refers to the physical and social environment related to navigation and interaction with the local people. Variables included "clearness of road signs and public facility signs, access to services in English, and friendliness of the Taiwanese people". The safety category referred the physical environment and the safety conditions in regard to various tourism attractions and services. The variables mentioned are "safety of recreational facilities, safety of social environments; safety of accommodation facilities, good public environmental hygiene, and good food hygiene". After the 15 individual items, the last question addressed the overall satisfaction with their trip to Taiwan. All questions were measured using a 5 point Likert scale in which "one" was the least satisfied and "five" was the most satisfied.

Price is an import factor of visitor satisfaction in general, but the main focus of the paper is to explore the effects of non-price factors on tourist satisfaction. The data set used in this research is provided by the Taiwan Tourism Bureau. There are 15 items related to visitor satisfaction in Taiwan, differentiated by three major non-price categories including "convenience, environment, safety, package tour for PT and overall satisfaction" in the questionnaire refers to all these non-price factors captured in the same questionnaire.

Cases were selected for this analysis when they reported mainland China as their country of residence and as their nationality. Residences of Hong Kong and Macau were excluded because they do not fall into the same category as mainland Chinese visitors and because the former group can travel with fewer restrictions to Taiwan.

\section{A conceptual framework}


In order to evaluate the changes of satisfaction over time, three time periods with different levels of regulation are proposed. Also, travel mode, PT and FIT, a control mechanism imposed by the Taiwan Tourism Bureau, are considered in this study, and the framework is illustrated in Figure 1.

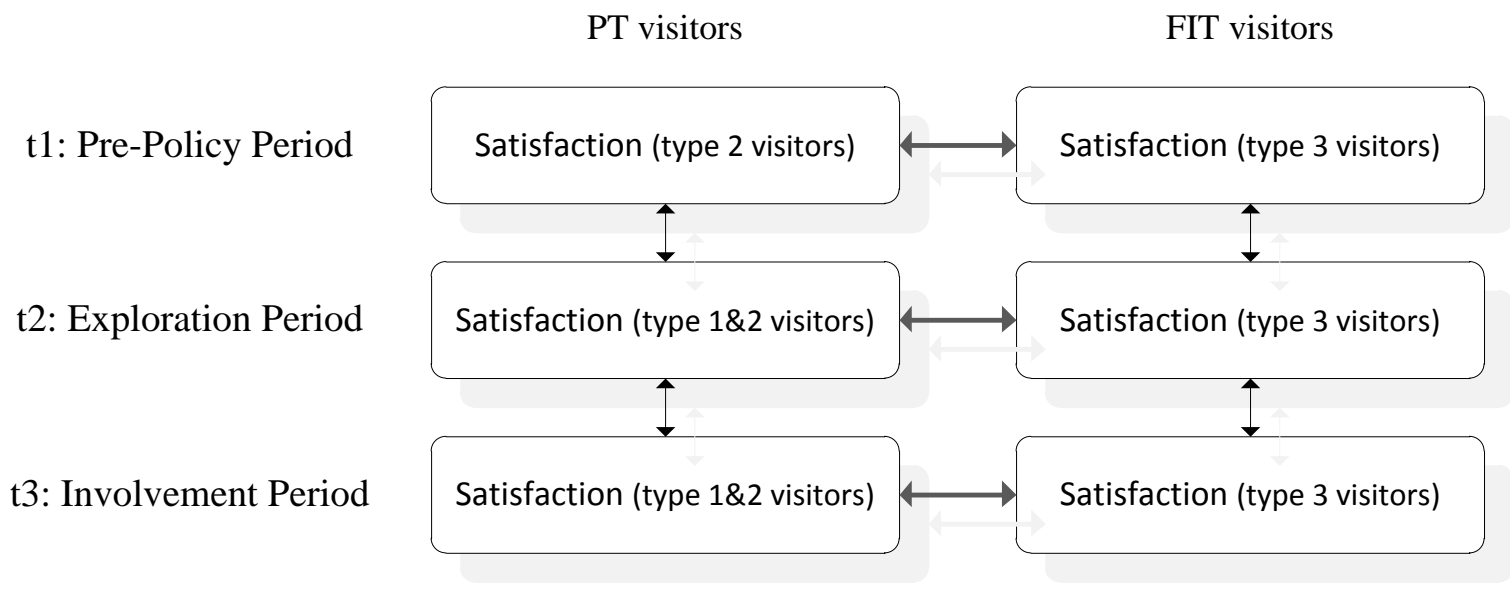

Figure 1: A Conceptual Framework

\section{Three stages of Chinese inbound development}

The three stages are determined based on the timing of the opening policy and the visitation volume of type 1 visitors. The annual inbound volume from China to Taiwan from 2002 to 2011 and the monthly records from July 2008 to Dec. 2011, after type 1 visitors were given the status to travel, are illustrated in Figure 2. The tourist inbound demand from mainland China is shown to dramatically increase since 2008; however the volume did not pick up until March 2009, 9 months after the "Opening up to mainland Chinese Tourist Arrivals" policy was implemented. The Taiwan Tourism Bureau (2009) has indicated that the reasons triggering the substantial jump on Chinese visitation were related to policy modifications, which specifically addressed the following issues: 1) requirement of package tour arrangements was relaxed: The policy allowed the minimum number of persons in a package tour to decrease from 10 people to 5 people and extended the length of stay of Chinese visitors to 15 days in Taiwan; 2) the visa application process was made more convenient: The "Cross-Strait Tourism Exchange Association" (CTEA) allowed more provinces in China to accept visa applications for travel to Taiwan while reducing the administrative procedures required to secure a travel visa; 3) information distribution was enhanced. More than 100 Chinese travel agencies were invited to Taiwan to experience various attractions and to establish collaboration with local businesses. It is expected that these China travel agencies have played a critical function for distributing travel information and facilitating potential visitors to Taiwan because organised package tour travel was the only travel mode permitted at that stage.

After March 2009, an increasing upward trend was observed with obvious peak demand in February, May and October of each year, which corresponds to the Chinese New Year holiday, the Golden week in May, and the National Day in October. To compare the tourist satisfaction over time, we have defined three periods according to the figure 2 in our study. 


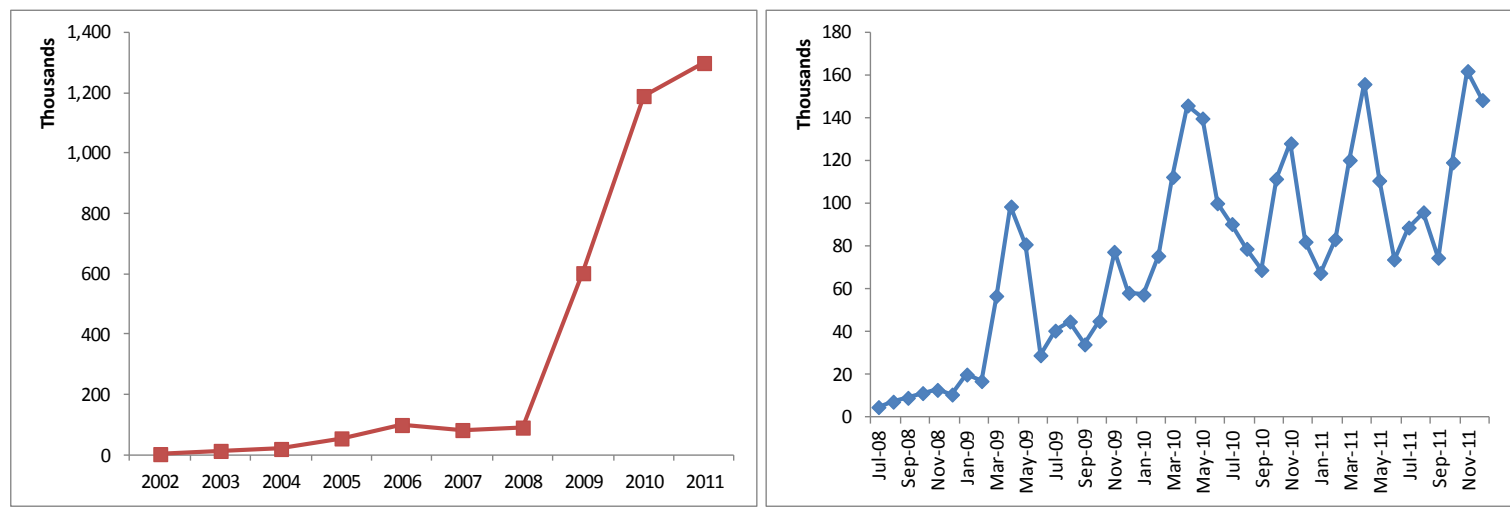

Figure 2: Inbound visitors from Mainland China to Taiwan (Source: National Immigration Agency, 2012b)

- Period 1: The "Pre-Policy Period", January 2007 to July 2008

This is related to the time when only selected type 2 and type 3 Chinese visitors were given the status to travel to Taiwan. In this period, the Chinese volume was quite limited, and visitors were prone to be professionals and society elites, whose demands in regard to service and attractions are quite different from the general regular visitors.

- Period 2: The "Exploration Period", August 2008 to March 2009

This timeline corresponds to the stage where Chinese visitor volume was relatively low during the early stage of the opening policy for the type 1 visitor. The "product" of travelling to Taiwan was novel to most Chinese nationals as well as to local travel agencies. Meanwhile, both managerial agencies, the Taiwan Strait Tourism Association (TSTA) and the CTEA, were negotiating frequently to determine the related procedures and requirements, leaving uncertainty with regard to the travel regulations during that period.

- Period 3: The "Involvement Period", April 2009 to December 2010.

This period was observed to exhibit a dramatic volume increase in Chinese visitors, which presents a strong growth rate from the demand side. "Exploration" and "Involvement" stages are adapted from the concepts of destination life cycle originally proposed by Butler (2006), whose study presented a pattern of visitation in terms of visitor volume.

We feel travel mode is another critical variable and hypothesise that each type of visitor may reveal different levels of satisfaction related to individual service items. This variable is brought into our study because not only the travel mode determines visitors' travel arrangements, service demanded, and the way they interact with the local society, but it also reflects the status of visitors, which is subject to different travel regulations. In our dataset, FIT only applies to type 3 visitors while PT includes both type 1 and 2 visitors.

\section{Findings}

\section{Demographic distribution of the sample}

The sample sizes of mainland China visitors datasets in the year 2007, 2008, 2009, and 2010 are $461,343,1255$, and 1860 , respectively (Table 2). There are 3919 tourists in total as a sample, which consists of 3449 PT tourists (88\%) and 470 FIT. The large increase of PTs during the involvement stage reflects the fact that type 1 visitors increased dramatically 
during the 3rd stage. Under this circumstance, the Taiwan Tourism Bureau increased their sample size accordingly.

Table 2: Distribution of samples by travel mode and time periods

\begin{tabular}{lcccc}
\hline Travel Mode & Pre-Policy & Exploration & Involvement & Total \\
\hline \hline PT & 439 & 355 & 2,655 & 3,449 \\
FIT & 162 & 116 & 192 & 470 \\
Total & 601 & 471 & 2,847 & 3,919 \\
\hline & & Percentage & \\
\hline PT & $73 \%$ & $75 \%$ & $93 \%$ & $12 \%$ \\
FIT & $27 \%$ & $25 \%$ & $7 \%$ & \\
\hline
\end{tabular}

The comparison of demographics for PT and FIT visitors are displayed in Table 3a. In general, PT visitors tend to be older than FIT visitors, especially because groups whose members are more than 40 years old account for more than two-thirds of this segment, while only $44 \%$ of FIT visitors fall into the same age group. Also, FIT visitors tend to have higher incomes and occupy a higher social status in regard to their occupations because more than $55 \%$ of them are either business managers or professionals. In comparison, PT visitors reported a higher percentage of retirees with a lower income distribution.

Table 3a: Demographics of PT and FIT visitors

\begin{tabular}{lccclcccc}
\hline & PT & FIT & Total & & PT & FIT & Total \\
\hline Sample size & 34,49 & 470 & 3,919 & $\begin{array}{c}\text { Sample size } \\
\text { Age }\end{array}$ & 34,49 & 470 & 3,919 \\
Gender & & & & & & & \\
Male & $43 \%$ & $56 \%$ & $44 \%$ & $12-19$ & $1 \%$ & $2 \%$ & $2 \%$ \\
Female & $57 \%$ & $44 \%$ & $56 \%$ & $20-29$ & $10 \%$ & $21 \%$ & $11 \%$ \\
Education & & & & $30-39$ & $21 \%$ & $32 \%$ & $23 \%$ \\
Primary school & $3 \%$ & $5 \%$ & $4 \%$ & $40-49$ & $28 \%$ & $21 \%$ & $27 \%$ \\
High school & $27 \%$ & $23 \%$ & $26 \%$ & $50-59$ & $21 \%$ & $12 \%$ & $20 \%$ \\
College+ & $69 \%$ & $71 \%$ & $69 \%$ & $60-65$ & $14 \%$ & $10 \%$ & $13 \%$ \\
Others & $0 \%$ & $0 \%$ & $0 \%$ & $66+$ & $5 \%$ & $1 \%$ & $4 \%$ \\
Missing & $1 \%$ & $1 \%$ & $1 \%$ & Job & & & \\
Annual income (\$US) & & & & Legislator/business & $13 \%$ & $20 \%$ & $14 \%$ \\
Below 9,999 & $37 \%$ & $17 \%$ & $35 \%$ & Professional & $25 \%$ & $34 \%$ & $27 \%$ \\
10,000-14,999 & $18 \%$ & $17 \%$ & $18 \%$ & Technician/Assistan & $2 \%$ & $5 \%$ & $3 \%$ \\
& & & & t & & & \\
15,000-29,999 & $12 \%$ & $19 \%$ & $13 \%$ & Office clerk & $20 \%$ & $10 \%$ & $19 \%$ \\
$30,000-39,999$ & $4 \%$ & $9 \%$ & $5 \%$ & Service worker & $4 \%$ & $3 \%$ & $4 \%$ \\
$40,000-69,999$ & $3 \%$ & $10 \%$ & $4 \%$ & Agricultural /fishery & $1 \%$ & $2 \%$ & $1 \%$ \\
$70,000-99,999$ & $1 \%$ & $4 \%$ & $1 \%$ & Labour & $1 \%$ & $1 \%$ & $1 \%$ \\
Over 100,000 & $1 \%$ & $3 \%$ & $1 \%$ & Homemaker & $9 \%$ & $9 \%$ & $9 \%$ \\
No fix income & $22 \%$ & $20 \%$ & $21 \%$ & Student & $4 \%$ & $6 \%$ & $4 \%$ \\
Missing & $2 \%$ & $1 \%$ & $2 \%$ & Retired & $20 \%$ & $8 \%$ & $19 \%$ \\
& & & & Other & $1 \%$ & $0 \%$ & $1 \%$ \\
\hline
\end{tabular}

In order to see if it is the composition structure of demographic variables in Table $3 \mathrm{a}$ collected in proportion to that in population, the age and gender information, the key social demographic, for all mainland China visitors to Taiwan (population) and the sample from 2007-2010 used here are presented in Table 3b, Table 3b shows that the sample and the 
population composition are very close to each other, although not identical. Thus, the sample has a pretty good representation of the population.

Table 3b: Population and sample distributions (Mainland Chinese Visitors 2007-2010)

\begin{tabular}{lccc}
\hline & Total Population & Population \% & Sample \% \\
\hline \hline Gender & & & \\
Male & 899,211 & $46 \%$ & $44 \%$ \\
Female & $1,063,410$ & $54 \%$ & $56 \%$ \\
Age & & & \\
$12-19$ & 70,399 & $2 \%$ & $2 \%$ \\
$20-29$ & 412,658 & $14 \%$ & $11 \%$ \\
$30-39$ & 563,658 & $19 \%$ & $23 \%$ \\
$40-49$ & 651,380 & $22 \%$ & $27 \%$ \\
$50-59$ & 563,201 & $19 \%$ & $20 \%$ \\
$60+$ & 638,971 & $22 \%$ & $17 \%$ \\
\hline
\end{tabular}

Source: National Immigration Agency, 2014

\section{Satisfaction level of Chinese tourists between PT and FIT}

The satisfaction score for PT and FIT Chinese visitors are listed and compared in Table 4. PT visitors consistently gave higher scores than FIT visitors on their satisfaction across 15 items as well as on their overall satisfaction level. In terms of performance by categories, "environment" received higher satisfaction, followed by "safety" and "convenience" from both segments. The top 3 most satisfied items were the "friendliness of Taiwanese people", "access to services in English" and "good public environmental hygiene", while the least satisfied were "efficiency of applying for a visa", "international transportation to Taiwan" and "communication facilities". The interesting pattern here is that the PT and FIT visitors reported identical satisfaction results for the top 3 most satisfied and the bottom 3 least satisfied items for their visit to Taiwan.

Before comparing the differences in opinions from PT and FIT visitors, KolmogorovSmirnov and Shapiro-Wilk normality tests were applied to test for the normal distribution. The tests showed a significant level of 0.01 for all items; thus, the non-parametric MannWhitney test was used for the comparisons of differences. All differences reported in Table 4 are significant (under 0.001), implying that PT and FIT visitors are different from each other in terms of the level of satisfaction; the results indicated that tourists are more satisfied with travel mode PT than travel mode FIT. Items that reported the largest difference were "efficiency of applying for a visa", "access to tourism information", and "good public environmental hygiene", where FIT visitors gave substantially lower scores. The first two items can be explained by the nature of the travel format. Given that travel agencies typically will take care of the process of securing a visa and also supply visitors with tourism information during the purchasing process, it is both labour and time efficient for PT tourists to enjoy these two perspectives. On the contrary, FIT visitors, the type 3 visitors who are Chinese nationals having permanent residency in a foreign country or working in a foreign country, may have higher difficulty in regard to securing a visa or obtaining Taiwan tourism information, to a certain degree because the number of Taiwanese embassies in foreign countries is quite limited. Items that exhibited the least difference between the two groups were "access to services in English" and "friendliness of the Taiwanese people". These two attributes, both receiving high satisfaction scores, can be interpreted as the stronghold of 
Taiwan tourism assets, which were enjoyed by Chinese visitors regardless of their travel format.

Overall, FIT and PT visitors ranked "environment" as areas that are the most satisfactory, and the differences in their opinions were quite small, suggesting that this category consistently performed well. On the contrary, the 7 items listed in the "convenience" category received lower scores. Most notably, FIT visitors felt that the performance on some perspectives was relatively weak. Items that require further improvement are visa applications, tourism information access, international transportation to Taiwan, and communication facilities.

Table 4: Satisfaction scores of PT and FIT with descriptive statistics (2007-2010)

\begin{tabular}{|c|c|c|c|c|c|c|c|}
\hline \multirow[t]{2}{*}{ Items } & \multirow[t]{2}{*}{ PT } & \multirow[t]{2}{*}{ FIT } & $\operatorname{Diff}^{1}$ & \multirow[t]{2}{*}{$\mathrm{PT}+\mathrm{FIT}$} & \multicolumn{3}{|c|}{$\mathrm{PT}+\mathrm{FIT}$} \\
\hline & & & Mean & & Std. & Skewness & Kurtosis \\
\hline Package tour & & & & & & & \\
\hline Tour guide service quality & 4.52 & & & & 0.68 & -1.41 & 1.94 \\
\hline Professionalism of interpretation & 4.49 & & & & 0.69 & -1.21 & 0.96 \\
\hline Transportation & 4.46 & & & & 0.66 & -0.95 & 0.53 \\
\hline Accommodations & 4.23 & & & & 0.75 & -0.73 & 0.37 \\
\hline Itinerary & 4.15 & & & & 0.79 & -0.73 & 0.41 \\
\hline Meals & 4.09 & & & & 0.83 & -0.68 & 0.15 \\
\hline Overall impression & 4.38 & & & & 0.67 & -0.78 & 0.08 \\
\hline Convenience & 4.01 & 3.69 & $0.32 * *$ & 3.97 & 0.74 & -0.09 & -0.95 \\
\hline Local transportation & 4.20 & 3.95 & $0.25 * *$ & 4.17 & 0.73 & -0.61 & 0.48 \\
\hline Customs procedures & 4.16 & 3.84 & $0.32 * *$ & 4.12 & 0.76 & -0.50 & -0.05 \\
\hline Immigration procedure & 4.14 & 3.83 & $0.31 * *$ & 4.10 & 0.76 & -0.48 & -0.08 \\
\hline Access to tourism information & 3.99 & 3.61 & $0.38 * *$ & 3.96 & 0.87 & -0.43 & -0.37 \\
\hline Communication facilities & 3.97 & 3.75 & $0.22 * *$ & 3.94 & 0.95 & -0.75 & 0.33 \\
\hline International transportation to Taiwan & 3.87 & 3.62 & $0.25 * *$ & 3.84 & 1.11 & -0.97 & 0.51 \\
\hline Efficiency of applying for a visa & 3.81 & 3.28 & $0.53 * *$ & 3.74 & 1.09 & -0.72 & 0.02 \\
\hline Environment & 4.49 & 4.27 & $0.22 * *$ & 4.47 & 0.53 & -0.64 & -0.23 \\
\hline Friendliness of Taiwanese people & 4.68 & 4.50 & $0.18 * *$ & 4.66 & 0.52 & -1.30 & 1.34 \\
\hline Access to services in English & 4.52 & 4.33 & $0.19 * *$ & 4.49 & 0.61 & -0.87 & 0.29 \\
\hline Clearness of road signs \& public signs & 4.29 & 3.99 & $0.30 * *$ & 4.25 & 0.75 & -0.68 & -0.08 \\
\hline Safety & 4.41 & 4.13 & $0.28 * *$ & 4.37 & 0.56 & -0.41 & -0.65 \\
\hline Safety of recreational facilities & 4.45 & 4.25 & $0.20 * *$ & 4.42 & 0.58 & -0.45 & -0.61 \\
\hline Safety of social environments & 4.42 & 4.19 & $0.23 * *$ & 4.40 & 0.61 & -0.51 & -0.49 \\
\hline Good public environmental hygiene & 4.44 & 4.08 & $0.36 * *$ & 4.39 & 0.66 & -0.78 & 0.24 \\
\hline Safety of accommodation facilities & 4.42 & 4.18 & $0.24 * *$ & 4.39 & 0.65 & -0.71 & -0.06 \\
\hline Good food hygiene & 4.34 & 4.04 & $0.30 * *$ & 4.30 & 0.69 & -0.64 & -0.06 \\
\hline Overall satisfaction & 4.38 & 4.13 & $0.25 * *$ & 4.35 & 0.61 & -0.38 & -0.59 \\
\hline
\end{tabular}

${ }^{\mathrm{I}}$ Difference of PT and FIT; **significantly different at 0.01 level; Std. indicates the standard deviation

\section{Satisfaction level of Chinese tourists over three periods}

The satisfaction score over the three time periods, "period 1: pre-policy", "period 2: exploration", and "period 3: involvement" are displayed in Table 5. In addition to reporting the mean score, we also computed the differences between periods and tested using the non- 
parametric Mann-Whitney test for their significance due to the fact that their distributions did not conform to a normal distribution. Based on the observed pattern, six types of responses were categorised. Types A, B, C describe factors or items that exhibited improved satisfaction over the time periods in general. Types $\mathrm{E}$ and $\mathrm{F}$ are factors or items that exhibited decreased satisfaction for one or two periods in the evaluation. Type D indicates that the level of satisfaction did not change during our evaluation period. Satisfaction is denoted as $\mathrm{S}$, and periods 1 to 3 are denoted as $t_{1}, t_{2}$, and $t_{3}$, respectively.

A: Satisfaction increases over the time periods: $\mathrm{S}_{\mathrm{t} 1}<\mathrm{S}_{\mathrm{t} 2}<\mathrm{S}_{\mathrm{t} 3}$

B: Satisfaction improves first and then remains steady: $S_{t 1}<S_{t 2}=S_{t 3}$

C: Satisfaction only improves during the 3rd period: $\mathrm{S}_{\mathrm{t} 1}=\mathrm{S}_{\mathrm{t} 2}<\mathrm{S}_{\mathrm{t} 3}$

D: Satisfaction does not change over the periods: $S_{t 1}=S_{t 2}=S_{t 3}$

E: Satisfaction improves first, then decreases during the 3rd period: $S_{t 1}<S_{t 2}>S_{t 3}$

F: Satisfaction decreases first, then increases during the 3rd period: $\mathrm{S}_{\mathrm{t} 1}>\mathrm{S}_{\mathrm{t} 2}<\mathrm{S}_{\mathrm{t} 3}$

The satisfaction scores with differences for the three time periods are presented in Table 5 . It shows that the overall level of Chinese tourist satisfaction toward Taiwan exhibited a statistically significant increase throughout the time periods from period 1 to period 3 , with the satisfaction scores ranging from 4.08, 4.34 to 4.40 suggesting that it was a type A performance. If we examine the individual factors or items, the satisfaction level was not as consistent as the overall satisfaction indicates. For all 22 items excluding the factors and overall satisfaction item, 10 out of 22 items $(45 \%)$ are categorised as A, which indicates improvement from period to period; 6 items $(27 \%)$ as B, representing that satisfaction remained the same disregarding government policy or visitor volume; 1 item (5\%) as $\mathrm{C}$, which means that the latest period (Involvement) performed better than the previous two periods in terms of tourist satisfaction; 5 items $(23 \%)$ as E, indicating the latest period performed worse than the previous two periods.

With respect to major categories, the area that received the most improvement in satisfaction was the "Convenience", which is classified as an A category in Table 5. In other words, the weakest link in the travel experience offered by Taiwan was improved upon, and the results suggest that the conveniences related to coming to and travelling within Taiwan were indeed improving during the study periods under consideration. On the contrary, the strong performing "Safety" category from Table 5 demonstrates a stagnated pattern, where visitor satisfaction stopped increasing during the later stage and the average "Environment" and "Package tour" factors also illustrated a decreased satisfaction score during the third stage as well.

Table 5: Satisfaction score for three time periods, 2007-2010

\begin{tabular}{lllll|lll|l}
\hline & \multicolumn{3}{c|}{ Satisfaction score (Mean) } & \multicolumn{4}{c|}{ Differences } \\
Three periods & $\mathrm{t}_{1}$ & $\mathrm{t}_{2}$ & $\mathrm{t}_{3}$ & $\mathrm{t}_{2}-\mathrm{t}_{1}$ & $\mathrm{t}_{3}-\mathrm{t}_{2}$ & $\mathrm{t}_{3}-\mathrm{t}_{1}$ & Type \\
\hline \hline \multicolumn{1}{c}{ Package tour } & & & & & & & \\
Tour guide service quality & 4.15 & 4.47 & 4.59 & $0.32^{* *}$ & $0.12^{* *}$ & $0.45^{* *}$ & $\mathrm{~A}$ \\
Professionalism of interpretation & 4.12 & 4.47 & 4.55 & $0.35^{* *}$ & $0.08^{* *}$ & $0.44^{* *}$ & $\mathrm{~A}$ \\
Transportation & 3.97 & 4.39 & 4.54 & $0.42^{* *}$ & $0.15^{* *}$ & $0.57^{* *}$ & $\mathrm{~A}$ \\
Accommodations & 3.84 & 4.40 & 4.27 & $0.55^{* *}$ & $-0.13^{*}$ & $0.42^{* *}$ & $\mathrm{E}$ \\
Itinerary & 3.71 & 4.31 & 4.21 & $0.60^{* *}$ & $-0.11^{*}$ & $0.49^{* *}$ & $\mathrm{E}$ \\
Meals & 3.76 & 4.29 & 4.12 & $0.52^{* *}$ & $-0.17^{*}$ & $0.36^{* *}$ & $\mathrm{E}$ \\
Overall impression & 4.01 & 4.38 & 4.45 & $0.37^{* *}$ & $0.06^{* *}$ & $0.44^{* *}$ & $\mathrm{~A}$ \\
\hline
\end{tabular}




\begin{tabular}{llll|lll|l}
\multicolumn{1}{c}{ Convenience } & 3.32 & 3.83 & 4.13 & $0.51^{* *}$ & $0.30^{* *}$ & $0.81^{* *}$ & $\mathrm{~A}$ \\
Efficiency of applying for a visa & 2.62 & 3.62 & 4.00 & $1.00^{* *}$ & $0.38^{* *}$ & $1.38^{* *}$ & $\mathrm{~A}$ \\
Access to tourism information & 3.63 & 3.70 & 4.05 & 0.06 & $0.36^{* *}$ & $0.42^{* *}$ & $\mathrm{C}$ \\
Customs procedures & 3.78 & 4.03 & 4.21 & $0.24^{* *}$ & $0.18^{* *}$ & $0.42^{* *}$ & $\mathrm{~A}$ \\
Immigration procedure & 3.76 & 4.00 & 4.19 & $0.24^{* *}$ & $0.19^{* *}$ & $0.42^{* *}$ & $\mathrm{~A}$ \\
Local transportation & 3.88 & 3.96 & 4.27 & $0.07^{* *}$ & $0.31^{* *}$ & $0.39^{* *}$ & $\mathrm{~A}$ \\
International transportation to Taiwan & 2.39 & 3.85 & 4.14 & $1.46^{* *}$ & $0.29^{* *}$ & $1.75^{* *}$ & $\mathrm{~A}$ \\
Communication facilities & 3.36 & 3.67 & 4.12 & $0.31^{* *}$ & $0.46^{* *}$ & $0.77^{* *}$ & $\mathrm{~A}$ \\
$\quad$ Environment & 4.22 & 4.56 & 4.50 & $0.34^{* *}$ & $-0.06^{*}$ & $0.29^{* *}$ & $\mathrm{E}$ \\
Clearness of road signs \& public signs & 4.05 & 4.39 & 4.27 & $0.34^{* *}$ & $-0.13^{* *}$ & $0.22^{* *}$ & $\mathrm{E}$ \\
Access to services in English & 4.24 & 4.58 & 4.53 & $0.34^{* *}$ & -0.04 & $0.30^{* *}$ & $\mathrm{~B}$ \\
Friendliness of Taiwanese people & 4.37 & 4.72 & 4.71 & $0.35^{* *}$ & -0.00 & $0.34^{* *}$ & $\mathrm{~B}$ \\
$\quad$ Safety & 4.10 & 4.42 & 4.42 & $0.32^{* *}$ & 0.01 & $0.33^{* *}$ & $\mathrm{~B}$ \\
Good public environmental hygiene & 4.08 & 4.38 & 4.46 & $0.31^{* *}$ & $0.08^{*}$ & $0.38^{* *}$ & $\mathrm{~A}$ \\
Good food hygiene & 4.08 & 4.32 & 4.35 & $0.25^{* *}$ & 0.02 & $0.27^{* *}$ & $\mathrm{~B}$ \\
Safety of accommodation facilities & 4.11 & 4.48 & 4.44 & $0.37^{* *}$ & -0.04 & $0.33^{* *}$ & $\mathrm{~B}$ \\
Safety of social environments & 4.11 & 4.48 & 4.44 & $0.36^{* *}$ & -0.03 & $0.33^{* *}$ & $\mathrm{~B}$ \\
Safety of recreational facilities & 4.13 & 4.53 & 4.47 & $0.40^{* *}$ & -0.06 & $0.34^{* *}$ & $\mathrm{~B}$ \\
$\quad$ Overall satisfaction & 4.08 & 4.34 & 4.40 & $0.26^{* *}$ & $0.07^{*}$ & $0.32^{* *}$ & $\mathrm{~A}$ \\
\hline
\end{tabular}

**significantly different at 0.01 level; *significantly different at 0.05 level

Attributes that deserve most managerial attention rest on the $\mathrm{E}$ items. The analysis results indicated that several E items were reported in travel package services, such as meals and itinerary, indicating that the satisfaction of PT visitors was compromised after visitor volume was greatly increased during period 3 with regard to tour package products. A furious pricewar competition among local travel agencies might be the main cause for such an observation. Using the price-war tactic to attract Chinese tourists appeared to be welcomed by Chinese tourists in general. The findings of Truong \& King (2009) indicated that Chinese tourists ranked the price attributes of a destination as the most important factor that affects their satisfaction. However, this tactic brings many side-effects. In Taiwan's example, this pricewar has forced travel agencies to operate below their break-even point (Sun, Sun \& Yu, 2011). In return, they had to earn their profits by receiving commissions from the retail sectors for introducing customers to as many specific outlets as possible, and the arrangement of accommodations and meals were downgraded to reduce the cost. Although the Taiwan Tourism Bureau (TTB) had foreseen this problem and imposed specific regulations on local travel agencies to regulate their arrangement for package tours, the bad quality issue caused by the price war competition was a repeated manner.

Different from Bowie and Change's observation (2005) that suggested that tour guide services are one of the most important factors affecting tourists' overall satisfaction in regard to package tours, Chinese PT visitors to Taiwan felt their overall package tour experience was compromised during the third stage even when they were more satisfied about the "tour guide service quality and their professionalism of interpretation". In other words, in the example of Taiwan, the central role played by the tour guide with respect to their services and professionalism did not play a critical part related to overall package tour satisfaction. To a large extent, the arrangement of hotels, food and the itinerary were the key.

Satisfaction level of PT visitors by three periods 
The satisfaction results for PT visitors by three stages are displayed in Table 6 . The overall satisfaction of PT visitors increased from 4.10 to 4.40 after the opening policy, then remained steady afterwards, a type B performance. The area that received the most improvement in regard to satisfaction is "Convenience". Items that received the largest jump between period 1 and period 3 were "international transportation to Taiwan (difference= 2.11)", "efficiency of applying for a visa (difference=1.55)", and "communication facilities (difference=0.94)". Given the ranking is based on a 5-point Likert scale, a " 2.11 point" increase on the score for the international transportation to Taiwan represent the visitors appreciate greatly the transportation conveniences created by the opening policy, which provides direct cross-strait air and marine transportation without routing through a third country. Similarity, "the ease of getting a visa and the access to communication facilities" demonstrates the streamlined crossstrait process, an outcome resulting from the cooperation of both sides of the managerial agencies involved.

Table 6: Satisfaction score of PT for time periods, 2007-2010

\begin{tabular}{|c|c|c|c|c|c|c|c|}
\hline \multirow[t]{2}{*}{ Three periods } & \multicolumn{3}{|c|}{ Satisfaction score (Mean) } & \multicolumn{3}{|c|}{ Differences } & \multirow[t]{2}{*}{ Type } \\
\hline & $\mathrm{t}_{1}$ & $\mathrm{t}_{2}$ & $\mathrm{t}_{3}$ & $t_{2}-t_{1}$ & $t_{3}-t_{2}$ & $t_{3}-t_{1}$ & \\
\hline Convenience & 3.24 & 3.90 & 4.15 & $0.66^{* *}$ & $0.26 * *$ & $0.91 * *$ & A \\
\hline Efficiency of applying for a visa & 2.48 & 3.74 & 4.03 & $1.26^{* *}$ & $0.30 * *$ & $1.55^{* *}$ & A \\
\hline Access to tourism information & 3.69 & 3.77 & 4.07 & 0.08 & $0.30 * *$ & $0.38 * *$ & $\mathrm{C}$ \\
\hline Customs procedures & 3.79 & 4.09 & 4.23 & $0.30 * *$ & $0.14 * *$ & $0.43 * *$ & A \\
\hline Immigration procedure & 3.77 & 4.06 & 4.21 & $0.29 * *$ & $0.15^{* *}$ & $0.44 * *$ & A \\
\hline Local transportation & 3.91 & 3.97 & 4.28 & $0.06^{* *}$ & $0.31 * *$ & $0.37 * *$ & A \\
\hline International transportation to Taiwan & 2.05 & 3.91 & 4.16 & $1.86^{* *}$ & $0.25 * *$ & $2.11 * *$ & A \\
\hline Communication facilities & 3.21 & 3.74 & 4.14 & $0.53^{* *}$ & $0.41 * *$ & $0.94 * *$ & A \\
\hline Environment & 4.25 & 4.64 & 4.52 & $0.39 * *$ & $-0.13 * *$ & $0.27 * *$ & $\mathrm{E}$ \\
\hline Clearness of road signs/public signs & 4.10 & 4.51 & 4.29 & $0.41 * *$ & $-0.22 * *$ & $0.19 * *$ & $\mathrm{E}$ \\
\hline Access to services in English & 4.25 & 4.65 & 4.54 & $0.41 * *$ & $-0.11 * *$ & $0.30 * *$ & $\mathrm{E}$ \\
\hline Friendliness of Taiwanese people & 4.40 & 4.76 & 4.72 & $0.36^{* *}$ & -0.04 & $0.32 * *$ & B \\
\hline Safety & 4.13 & 4.50 & 4.44 & $0.37 * *$ & -0.06 & $0.31 * *$ & B \\
\hline Good public environmental hygiene & 4.12 & 4.48 & 4.48 & $0.36^{* *}$ & 0.00 & $0.36^{* *}$ & B \\
\hline Good food hygiene & 4.11 & 4.42 & 4.36 & $0.31 * *$ & -0.05 & $0.25 * *$ & B \\
\hline Safety of accommodation facilities & 4.13 & 4.55 & 4.45 & $0.42 * *$ & $-0.11 *$ & $0.31 * *$ & $\mathrm{E}$ \\
\hline Safety of social environments & 4.15 & 4.54 & 4.45 & $0.40 * *$ & $-0.09 *$ & $0.31 * *$ & $\mathrm{E}$ \\
\hline Safety of recreational facilities & 4.15 & 4.58 & 4.48 & $0.43 * *$ & $-0.11 * *$ & $0.33 * *$ & $\mathrm{E}$ \\
\hline Overall satisfaction & 4.10 & 4.40 & 4.42 & $0.31 * *$ & 0.01 & $0.32 * *$ & B \\
\hline
\end{tabular}

**significantly different at 0.01 level; *significantly different at 0.05 level

Besides the positive changes on items related to convenience, several areas reported a decrease in levels of satisfaction during period 3, referred to as the type E category. PT tourists were not satisfied with, ranked by differences in scores, "clearness of road signs and public utility signs", "access to services in English", "safety of accommodation facilities", "safety of recreational facilities" and "safety of social environments. Although these five items received very high marks during period 2, all above 4.5 out of 5 points, some recess in scores indicates that the performance on these five factors had room for improvement. 
One major area in the above-description is related to the safety issue. Once an accident involves Chinese visitors, repeated media exposure is broadcast in both Taiwan and China. The first large accident involving fatalities was reported in April 2009 when a tour bus with Chinese visitors was accidently smashed by a crane when passing through a construction site. On May 2009, repeated news regarding rockslide accidents in Taroko National Park and a train-vehicle crash in the Alishan National Scenic Area raised alarm regarding the safety issues related to travelling in Taiwan. On October 2010, a tour bus with 19 Chinese passengers was hit by a rockslide during a typhoon on the east coast of Taiwan, and all passengers were declared dead. These accidents created negative images in terms of safety issues. Most notably, they were mainly associated with Taroko National Park and the Alishan National Scenic Area, which are among the favourite attractions for Chinese visitors. In response to these issues, precautionary steps were taken by providing helmets to visitors when they visited the gorge area of the national park, and travel-related insurance became mandatory in 2010. However the negative publicity has left a mark on the visitor satisfaction.

For the other two aspects, "clearness of road signs and public facility signs" and "access to services in English", PT visitors gave very high scores of 4.51 and 4.65, respectively, during the exploration period, but this decreased during the 3rd stage. Currently there are no clear explanations for such an observation because PT tourists are limited to a pre-arranged itinerary and are accompanied by tour guides most of the time, so the need to navigate themselves and to gain access to services in English is quite limited. The only speculation rests on the changing demographics during period 2 to period 3 for PT visitors. From Table 2, in period 3, relatively, PT visitors were less educated (more high school degrees than college), older (more people above 60), and there was a higher percentage of retirees. Older PT visitors may have difficulty reading signs and gaining access to services in English, resulting in lower scores being reported.

\section{Satisfaction level of FIT visitors over three periods}

The satisfaction results for FIT visitors for the three stages are displayed in Table 7 . The overall satisfaction score for FIT visitors to Taiwan was the same for periods 1 and 2 and then increased during period 3. In other words, the opening policy did not impact the satisfaction of FIT visitors as much as it did PT tourists. In terms of major categories, "environment" and "safety" received higher satisfaction than "convenience", but the last category received the largest extent of improvement over the study period.

For the 15 individual items, one is ranked as the " $\mathrm{A}$ " type, improving over the three periods, which is the "international transportation to Taiwan" category. Four items were categorised as "B", 5 items as "C", 4 items as "D", and one as "F". In general, two-thirds of the 15 individual items experienced improved satisfaction either during period 2 or period 3 (types A, B, C). "Customs procedures, immigration procedures, clearness of road signs and public facility signs, and good food hygiene" were areas that did not change over the evaluation periods (type D). The only type F variable was "communication facilities", such as the availability of international public phones or access to the Internet, rated as less satisfactory during period 2 when compared to periods 1 and 3. The consistent low ranking of satisfaction toward this attribute means that the communication channels, either online or by phone, have not yet been made easy and convenient for international visitors.

Table 7: Satisfaction score for FIT visitors for time period 2007-2010 


\begin{tabular}{l|lll|lll|l} 
& $\mathrm{t}_{1}$ & $\mathrm{t}_{2}$ & $\mathrm{t}_{1}$ & $\mathrm{t}_{2}-\mathrm{t}_{1}$ & $\mathrm{t}_{3}-\mathrm{t}_{2}$ & $\mathrm{t}_{3}-\mathrm{t}_{1}$ & \\
\hline \hline \multicolumn{1}{c}{ Convenience } & 3.55 & 3.64 & 3.85 & 0.09 & $0.21^{*}$ & $0.30^{* *}$ & $\mathrm{C}$ \\
Efficiency of applying for a visa & 3.00 & 3.26 & 3.53 & 0.26 & 0.28 & $0.53^{*}$ & $\mathrm{C}$ \\
Access to tourism information & 3.49 & 3.47 & 3.83 & -0.02 & $0.36^{*}$ & $0.34^{* *}$ & $\mathrm{C}$ \\
Customs procedures & 3.75 & 3.83 & 3.93 & 0.08 & 0.10 & 0.19 & $\mathrm{D}$ \\
Immigration procedure & 3.75 & 3.81 & 3.90 & 0.06 & 0.09 & 0.15 & $\mathrm{D}$ \\
Local transportation & 3.80 & 3.91 & 4.10 & 0.11 & 0.19 & $0.31^{* *}$ & $\mathrm{C}$ \\
International transportation to Taiwan & 3.31 & 3.66 & 3.86 & $0.35^{*}$ & $0.21^{*}$ & $0.56^{* *}$ & $\mathrm{~A}$ \\
Communication facilities & 3.74 & 3.51 & 3.90 & $-0.23^{*}$ & $0.39^{*}$ & $0.16^{*}$ & $\mathrm{~F}$ \\
$\quad$ Environment & 4.14 & 4.32 & 4.35 & $0.18^{* *}$ & 0.03 & $0.21^{* *}$ & $\mathrm{~B}$ \\
Clearness of road signs \& public signs & 3.93 & 4.04 & 4.00 & 0.12 & -0.04 & 0.07 & $\mathrm{D}$ \\
Access to services in English & 4.21 & 4.34 & 4.43 & 0.13 & 0.08 & $0.22^{* *}$ & $\mathrm{C}$ \\
Friendliness of Taiwanese people & 4.29 & 4.59 & 4.64 & $0.30^{* *}$ & 0.05 & $0.35^{* *}$ & $\mathrm{~B}$ \\
$\quad$ Safety & 4.02 & 4.17 & 4.20 & $0.16^{*}$ & 0.03 & $0.19^{* *}$ & $\mathrm{~B}$ \\
Good public environmental hygiene & 3.96 & 4.09 & 4.18 & 0.14 & 0.08 & $0.22^{* *}$ & $\mathrm{C}$ \\
Good food hygiene & 3.98 & 4.04 & 4.08 & 0.06 & 0.04 & 0.10 & $\mathrm{D}$ \\
Safety of accommodation facilities & 4.03 & 4.21 & 4.28 & $0.17^{* *}$ & 0.08 & $0.25^{* *}$ & $\mathrm{~B}$ \\
Safety of social environments & 4.02 & 4.28 & 4.27 & $0.26^{* *}$ & -0.01 & $0.25^{* *}$ & $\mathrm{~B}$ \\
Safety of recreational facilities & 4.08 & 4.35 & 4.34 & $0.28^{* *}$ & -0.01 & $0.27^{* *}$ & $\mathrm{~B}$ \\
$\quad$ Overall satisfaction & 4.04 & 4.13 & 4.21 & 0.09 & 0.08 & $0.17^{*}$ & $\mathrm{C}$ \\
\hline
\end{tabular}

**significantly different at 0.01 level; *significantly different at 0.05 level

\section{Changes in pattern of satisfaction level between PT and FIT over three periods}

In order to understand changing patterns of satisfaction between PT and FIT over the three periods, we compared the satisfaction by travel mode and plotted the differences in the satisfaction score to reveal the pattern. In Table 8, visitors by travel mode demonstrated different satisfaction patterns than were demonstrated when merging these two together (total samples). We re-labelled A, B, C as "+", D as "=", and E or F as "_.". The positive sign indicates that the satisfaction increased during either period 2 and/or period 3, while the negative sign indicates that the satisfaction score was decreased during either of the time periods.

In the convenience category, PT visitors were more satisfied over time while FIT visitors indicated that satisfaction either remained the same or decreased by a small amount. Also, most FIT visitors gave scores on the convenience category less than 4.0, indicating this area deserves attention from the Taiwan Tourism Bureau to further streamline the process of immigrations, visa applications, tourism information distribution and the availability of convenient international and domestic transportation. In the case of the environment category, friendliness of the Taiwanese people" always received a high score, but the "sign system for roads and public facilities" requires enhanced performance for both PT and FIT visitors. In terms of safety, FIT visitors generally reported improving levels of satisfaction while PT visitors were not so comfortable about some safety aspects with regard to attractions, hotel facilities and the social environment. This is maybe related to the negative publicity associated with occasional PT accidents in Taiwan. 
One thing worth mentioning is that PT and FIT visitors may report contrary satisfaction scores toward the same service attribute, which cannot be identified through the overall sample because the results are averaged out. For example, PT visitors were increasingly satisfied with communication facilities while FIT visitors indicated that their satisfaction did not improve but rather declined. Similarly, PT visitors indicated that the "safety of accommodation facilities" was not so satisfying while FIT visitors felt the opposite over time. Over the 15 individual items, five items, "communication facilities, access to services in English, safety of accommodation facilities, safety of recreational facilities, and safety of social environments" reported contrary results between FIT and PT visitors, indicating that travel mode has specific implications on how services are delivered, expected, and experienced by Chinese visitors.

Table 8: Satisfaction type for PT, FIT and overall Chinese visitors

\begin{tabular}{|c|c|c|c|}
\hline Satisfaction type & $\mathrm{PT}$ & FIT & $\mathrm{PT}+\mathrm{FIT}$ \\
\hline \multicolumn{4}{|l|}{ Package tour } \\
\hline Transportation & + & & \\
\hline Tour guide service quality & + & & \\
\hline Professionalism of interpretation & + & & \\
\hline Accommodations & - & & \\
\hline Itinerary & - & & \\
\hline Meals & - & & \\
\hline Overall impression & + & & \\
\hline Convenience & + & + & + \\
\hline Efficiency of applying for a visa & + & + & + \\
\hline Access to tourism information & + & + & + \\
\hline Customs procedures & + & $=$ & + \\
\hline Immigration procedure & + & $=$ & + \\
\hline Local transportation & + & + & + \\
\hline International transportation to Taiwan & + & + & + \\
\hline Communication facilities & + & - & + \\
\hline Environment & - & + & - \\
\hline Clearness of road signs and public facility signs & - & $=$ & - \\
\hline Access to services in English & - & + & + \\
\hline Friendliness of Taiwanese people & + & + & + \\
\hline Safety & + & + & + \\
\hline Good public environmental hygiene & + & + & + \\
\hline Good food hygiene & + & $=$ & + \\
\hline Safety of accommodation facilities & - & + & + \\
\hline Safety of social environments & - & + & + \\
\hline Safety of recreational facilities & - & + & + \\
\hline Overall satisfaction & + & + & + \\
\hline
\end{tabular}

We further plot the satisfaction score into a two-by-two figure where the $\mathrm{x}$-axis represents the differences in satisfaction between period 1 and period 2, and the y-axis represents the difference between period 2 and 3. Quadrant I repents attributes that have improved from period 1 to period 2, and then to period 3, respectively. Quadrant IV represents items for which visitors were less satisfied during period 3 as compared to period 2 . 
Two observations were drawn from Figure 3. First of all, PT visitors experienced higher satisfaction jumps from period 1 to period 2 for selected items, including "international transportation to Taiwan (difference=2.11)", "efficiency of applying for a visa (difference $=1.55$ ), and "communication facilities (difference=0.94). On the contrary, the improvement of satisfaction for FIT visitors tended to be more marginal, less than 0.5 out of 5 points. The opening policy impacted more with regard to the "convenience" aspects for PT visitors than it did for FIT visitors, as supported by their satisfaction evaluations. Secondly, PT visitors reported more attributes in quadrant IV, representing a dramatic increase of PT visitor daily quotas, and the high visitation volume negatively influenced some aspects of their satisfaction for traveling to Taiwan. Specifically, their tour package arrangements for hotels, meals, itineraries, and safety issues for facilities and the environment were matters that were directly linked with the Taiwan tourism capacity for delivering a high-quality and safe travel experience when a segment experienced a $144 \%$ annual growth rate over the past three years. The premise of providing good quality service to obtain positive word of mouth and higher loyalty in regard to achieving sustainable tourism volume was compromised on these service attributes.

Figure 3: Satisfaction difference for PT and FIT visitors

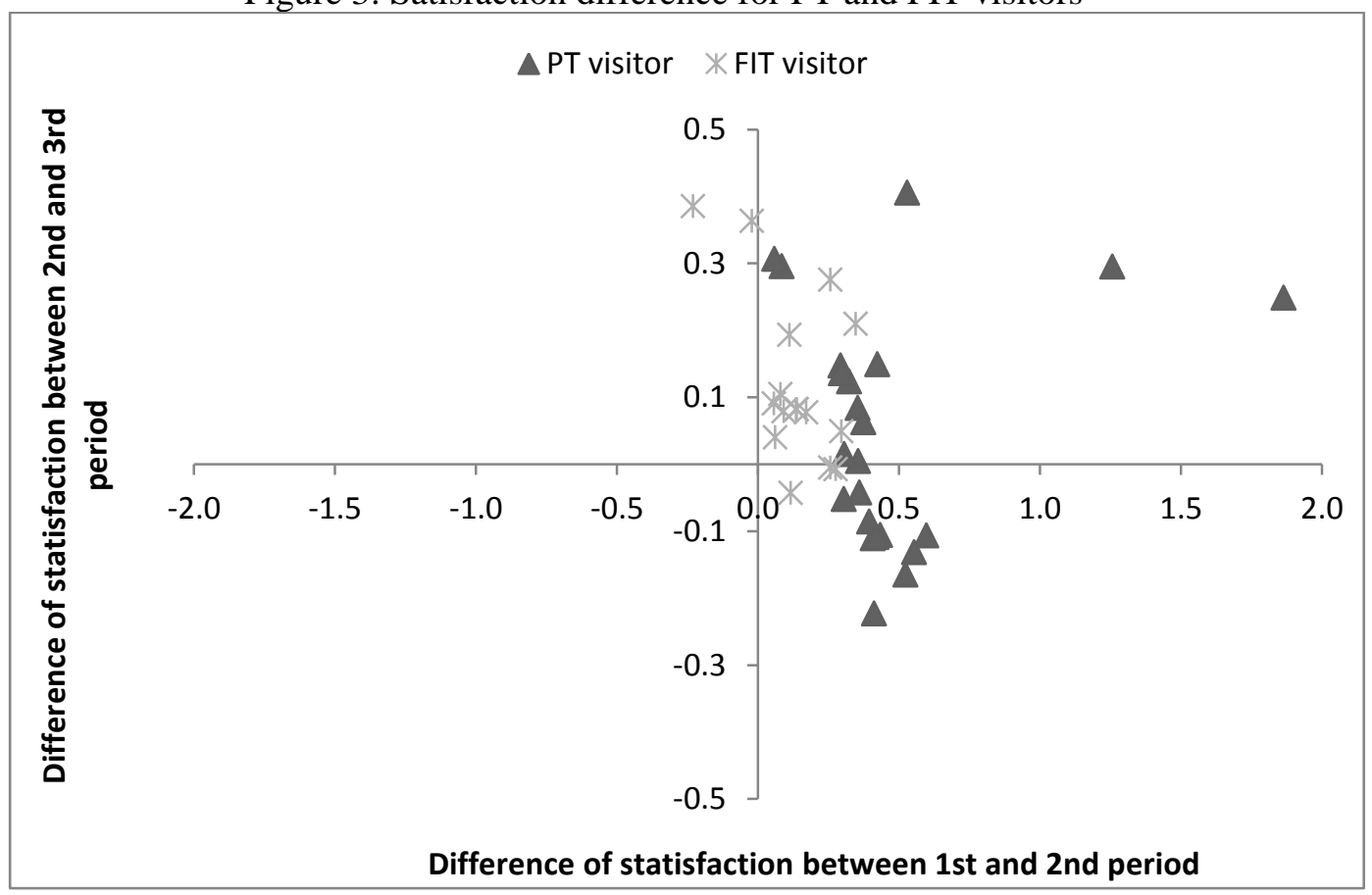

\section{Discussions}

Visitors' satisfaction reflects a dynamic between the demand (volume and expectation) and the supply (capacity and service delivery) (Kandampully, 2000). In the context of this study, satisfaction represents how well the destination absorbs tourism when the visitor segment demonstrated a strong demand growth. To assess the multi-perspective tourism capacity, Getz (1982) proposed six criteria for evaluation: physical (tangible resources), economic, ecological, social/cultural, political/administrative, and perceptions of visitors. Due to the limits of using secondary data (the pre-determined Taiwan Tourism Bureau inbound visitor survey), the attributes covered in the analysis can only be related to physical capacity 
(lodging, transportation, meals, itinerary, signage, communication facilities), social/cultural capacity (resident attitudes and safety issues), and the policy capacity (visa applications, tourism information availability, customers and immigration procedures). Two observations were drawn from the results.

Firstly, interacting forces between policy, physical capacity, and social factors in determining tourism capacity are observed. Due to the political complexity cross strait, the intention to minimize the possible illegal activities of Chinese visitors is mitigated through intensive regulations, which was an attempt to avoid the possible political disputes and social antagonism toward Chinese visitors (Mainland Affairs Council, 2009). In a way, regulation is employed to increase the tourism capacity on the political and social perspectives. However, the original good intention is compromised because the highly regulated market has its own mechanism to operate, which in turn reduce the tourism capacity on some aspects. The preparatory measures of mandating type 1 visitors to enter Taiwan only by package tours has generated furious price competition among Taiwan travel agencies and displayed a strong concentrated pattern among selected tourism attractions. These two factors lead to the deteriorated quality of services. Performances on lodging, meal and the overall arrangement of itinerary were downgraded not only because of the facility bottleneck but also due the inferior services and products that a local travel agency can afford to offer. No win-win situation was observed in this context.

Secondly, the assumption that a rapid change in visitation can have detrimental impacts on all components at destinations is challenged in our study. Getz (1983) advocated that the merits of large versus small scale, slow versus rapid growth, concentrated versus dispersed tourism development should be tested in each situation to understand the relationship of market growth and its impacts. In our study, the Chinese market is an excellent example of large scale, rapid growth having a concentrated mass tourism format. Given this context, several aspects of the tourism capacity are still highly praised with significant improvements in satisfaction over time (Table 5), including "tour guide service attitude, professionalism of their interpretation services, convenience of transportation to and within Taiwan, efficiency of applying for a visa, customs and immigration procedures, and public hygiene". The first two attributes mentioned above are related to the service quality of tour guides, which are rated over 4.5 out of 5 points. This demonstrates that high quality human resources from travel agencies are quite resilient when subjected to a strong demand pattern and remain an important asset for Taiwan. In comparison, "transportation to and within Taiwan, visa applications, customs and immigration procedures" are more related to administrative policies, which are largely dictated by cross-government and cross-region negotiations. Currently, the satisfaction score of these few attributes are averaged at only around 4.0 points, substantially lower than the other items. Although these weakest links in the tourism capacity are improving over time, they remain the areas that deserve continuous cooperation between the cross-strait governments.

According to Truong \& King (2009)'s study, which analysed the degree of importance of different destination attributes in Vietnam, Chinese tourists visiting Vietnam regarded attributes such as prices, Chinese languages spoken, natural scenery, brochures, overall safety and friendliness as highly relevant to their satisfaction. If we assume that Chinese tourists would consider similar attributes which have largely contributed to their satisfaction when they have travelled outside of China, then it can be carefully suggested that tourists from mainland China travelling to Taiwan would consider "access to tourism information", "friendliness of the Taiwanese people", and "safety of social environment" as the most 
important items. The findings show that the degree of tourist satisfaction in the later stages was higher than it was in earlier stages regarding the items of "access to tourism information" and "friendliness of the Taiwanese people"; however, the satisfaction with "safety of social environment" at the third stage (Involvement) was lower than in the second stage (Exploration), which may be worth attention from policy makers.

Wong and Law (2003) studied the relationship between Chinese culture and tourist behaviour and found that Hong Kong Chinese tourists enjoy travel in groups and care about safety. Since mainland Chinese and Hong Kong Chinese share similar aspects of Chinese culture, it can be carefully summarised that mainland tourists may prefer package tours as compared to independent travel because the former can provide a chance to travel in groups and a safe environment. This may explain the findings of the current research that FIT visitors did not experience increased satisfaction levels as compared to PT visitors. Another factor which is attributed to the lower satisfaction level of FIT visitors could be that FIT consists of tourists mainly consisting of type 3 visitors, Chinese nationals with permanent residence in a different country. Type 3 visitors may have higher education and income levels, and their travels are likely to involve seeking knowledge and prestige. According to Kau and Kim's (Kau \& Lim, 2005) study evaluating the satisfaction of Chinese tourists in Singapore, the Prestige/Knowledge seekers were the least satisfied group across various destination attributes compared to the other three groups, Family/Relaxation, Novelty, Adventure/Pleasure seekers. It can be recommended that in order to improve the satisfaction level of FIT visitors, it is important to create a multicultural experience environment and to show a high level of respect to tourists in Taiwan.

\section{Conclusions}

The purpose of this study is to analyse impact of policy on tourist satisfaction which is hardly found from literature. Satisfaction levels of Chinese visitors to Taiwan across three different time periods, differentiated by visitor volumes between January 2007 and December 2010 are compared in this study. The overall satisfaction with package tour services increased after the ban for travel to Taiwan was lifted in 2008 but has remained constant since then. When the detailed items are analysed, due to the low-price phenomenon characteristic of package tours, Chinese visitors have expressed a lower level of satisfaction toward arrangements related to lodging, meals, and itinerary, but have had positive comments regarding transportation, tour guide service attitude, and interpretation services. As for the overall travel experiences in Taiwan, the environmental component received lower satisfaction scores. The main causes for a reduced satisfaction level in the "environment" component were associated with "safety issues", "clearness of road signs and public facility signs", and "services in English". On the other hand, components of the "convenience of travel to and within Taiwan" and "travel agency services" were deemed to perform better over time. Generally speaking, package tour visitors were more satisfied with individual service items than FIT visitors but reported a larger variation of their satisfaction scores over time.

With an annual growth rate of $144 \%$ for Chinese visitors to Taiwan from the period 2008 to 2010 , it is a great challenge to keep up the satisfaction level of customers as well as to implement policies related to individual components. Our study only addressed the satisfaction level during the first three years of this new source market, which is expected to grow in the future more rapidly after the daily quota of mainland Chinese visitors is gradually increased, and the FIT policy is relaxed over time. A close inspection of future satisfaction levels by visitor volume deserves further exploration. 
In terms of statistical tests applied in this study, a more robust approach of normality test is applied in order to determine either using parametric or non-parametric method.

\section{Contributions and implications}

The main contributions that are offered by this paper are as follows:

1) There is little research on how open policy affects tourist satisfaction in the literature. The satisfaction of mainland Chinese tourists to Taiwan is a typical case study for the policy impact on tourist satisfaction.

2) The purpose of this study is to provide in-depth analysis of how the policy impact on tourism satisfaction. Three periods (Pre-Policy, Exploration and Involvement Periods) and two travel modes (PT versus FIT) are analysed and evaluated. The cycle of the three periods related to policy is rarely studied in the literature.

3) The theoretical approach of normality test (Kolmogorov-Smirnov and Shapiro-Wilk) is tested before applying parametric or non-parametric approach which is rarely used in the literature; the common method in the literature is either using T-test (parametric) or Mann-Whitney test (non-parametric) directly which is not a proper approach from the theory perspective.

The results provide the guidance for the government and local tourism organizations, such as how to implement policy and improve customer satisfaction. The implications of this research are as follows:

1) Provide the guidance to travel agencies on improving the service quality, such as PT may increase the price in order to arrange high quality of lodging, meals, and itinerary.

2) The service regarding to the environment is a big issue since the lower satisfaction scores for both PT and FIT tours. The study illustrated that the priority task is to make road signs and public signs clearly, and to provide bilingual language English and Chinese service for tourists and road signs.

\section{References:}

Albayrak T., \& Caber M. (2013). The symmetric and asymmetric influences of destination attributes on overall visitor satisfaction. Current Issues in Tourism, 16(2), 149-166.

Alegre, J., \& Garau, J. (2010). Tourist satisfaction and dissatisfaction. Annals of Tourism Research, 37(1), 52-73.

Akama, J., S., \& Kieti, D. M. (2003). Measuring tourist satisfaction with Kenya's wildlife safari: a case study of Tsavo West National Park. Tourism Management, 24(1), 73-81.

Anastasiadou, C. (2008). Tourism interest groups in the EU policy arena: characteristics, relationships and challenges. Current Issues, 11(1), 24-62.

Bowie, D., \& Chang, J. C. (2005). Tourist satisfaction: A view from a mixed international guided package tour. Journal of Vacation Marketing, 11(4), 303-322.

Butler, R. W. (1980). The concept of a tourist area cycle of evolution: Implications for management of resources. Geographer / Le Géographe canadien, 24(1), 5-12. 
Butler, R. W. (Ed.). (2006). The tourism area life cycle vol.2. Clevedon UK: Channel View Publications.

de Rojas, C. \& Camarero, C. (2008). Visitors' experience, mood and satisfaction in a heritage context: Evidence from an interpretation center. Tourism Management, 29(3),

del Bosque, I. A. R., Martín, H. S., \& Collado, J. (2006). The role of expectations in the consumer satisfaction formation process: Empirical evidence in the travel agency sector. Tourism Management, 27(3), 410-419.

Getz, D. (1982). A rationale and methodology for assessing capacity to absorb tourism. Ontario Geography, 19, 92-102.

Getz, D. (1983). Capacity to absorb tourism: Concepts and implications for strategic planning. Annals of Tourism Research, 10(2), 239-263.

Geva, A., \& Goldman, A. (1991). Satisfaction measurement in guided tours. Annals of Tourism Research, 18(2), 177-185.

Griffin, K. \& Stacey, J. (2011). Towards a "tourism for all” policy for Ireland: achieving real sustainability in Irish tourism. Current Issues in Tourism, 14(5), 431-444.

Huang, S., Hsu, C. H. C., \& Chan, A. (2010). Tour guide performance and tourist satisfaction: a study of the package tours in Shanghai. Journal of Hospitality \& Tourism Research, 34(1), 3-33.

Hui, T. K., Wan, D., \& Ho, A. (2007). Tourists' satisfaction, recommendation and revisiting Singapore. Tourism Management, 28(4), 965-975.

Li, W. J. Jessie, \& Carr, N. (2004). Visitor Satisfaction. International Journal of Hospitality \& Tourism Administration, 5(3), 31-48.

Kandampully, J. (2000). The impact of demand fluctuation on the quality of service: a tourism industry example. Managing Service Quality, 10(1), 10-19.

Kau, A. K., \& Lim, P. S. (2005). Clustering of Chinese tourists to Singapore: an analysis of their motivations, values and satisfaction. International Journal of Tourism Research, 7(4-5), 231-248.

Lin, Y. H., \& Lin, K. (2006). Assessing mainland Chinese visitors' satisfaction with shopping in Taiwan. Asia Pacific Journal of Tourism Research, 11(3), 247-268.

Lee I. S., Lee T. J., \& Arcodia C. (2013). The effect of community attachment on cultural festival visitors' satisfaction and future intentions. Current Issues in Tourism, 1, 1-13.

Mainland Affairs Council. (2009). Promotion program instructions of the opening policy on mainland China tourist to visit Taiwan. (In chinese) http://www.mac.gov.tw/ct.asp?xItem $=68289 \& \mathrm{ctNode}=6621 \& \mathrm{mp}=1$

Millán, Á., \& Esteban, Á. (2004). Development of a multiple-item scale for measuring customer satisfaction in travel agencies services. Tourism Management, 25(5), 533-546.

National Immigration Agency. (2012a). Regulations for China residents to enter or exit Taiwan.

http://www.immigration.gov.tw/lp.asp?ctNode=29651\&CtUnit=16411\&BaseDSD=105 $\& \mathrm{mp}=1$

National Immigration Agency. (2012b). Statistics of mainland China tourist to visit Taiwan (In Chinese)

http://www.immigration.gov.tw/lp.asp?ctNode=29699\&CtUnit=16434\&BaseDSD=7\& $\mathrm{mp}=1$

National Immigration Agency. (2014). Statistics of mainland Chinese visitors to Taiwan. http://www.immigration.gov.tw/lp.asp?ctNode=29699\&CtUnit=16434\&BaseDSD=7\&mp=1

Pavlic, I., Perucic, D. \& Portolan, A. (2011). Tourists' satisfaction as an important tool for increasing tourism destination competitiveness in the globalization conditions - the case of Dubrovnic-Neretva county. International Journal of Management, 13(3), 591-599.

Pforr, C. (2006). Tourism policy in the making: an Australian network study. Annals of 
Tourism Research, 33(1), 87-108.

Pizman, A., Neuman, Y. \& Reichel, (1979). Tourist Satisfaction, Uses and Misuses. Annals of tourism research, 6, 96-107.Oliver, R. L. (1997). Satisfaction: a behavioral perspective on the consumer: McGraw Hill.

Qu, H., \& Li, I. (1997). The characteristics and satisfaction of mainland Chinese visitors to Hong Kong. Journal of Travel Research, 35(4), 37-41.

Singh, J. (1991). Understanding the structure of consumers' satisfaction evaluations of service delivery. Journal of the Academy of Marketing Science, 19(3), 223-244.

Söderlund, M. (1998). Customer satisfaction and its consequences on customer behaviour revisited: The impact of different levels of satisfaction on word-of-mouth, feedback to the supplier and loyalty. International Journal of Service Industry Management, 9(2), 169-188.

Song, H., Li, G., van der Veen, R., \& Chen, J. L. (2011). Assessing mainland Chinese tourists' satisfaction with Hong Kong using tourist satisfaction index. International Journal of Tourism Research, 13(1), 82-96.

Sun, J.-S., Sun, Y.-Y., \& Yu, H.-L. (2011). The economic impact of China-Taiwan ferrycruise traffic. Journal of Logistics and Shipping Economics, 45, 83-92.

Taiwan Tourism Bureau. (2009). The cross-strait direct flights enhance mainland tourist to visit Taiwan and increase business opportunities (In Chinese) http://admin.taiwan.net.tw/news/news_d.aspx?no=160\&d=1973\&tag=4

Taiwan Tourism Bureau. (2010). 2009 Annual Survey Report on Visitors Expenditure and Trends in Taiwan. Taipei: Taiwan Tourism Bureau, M.O.T. Republic of China.

Taiwan Tourism Bureau. (2012a). mainland Tourists Traveling to Taiwan (In Chinese) http://admin.taiwan.net.tw/news/news2.aspx?no=160

Taiwan Tourism Bureau. (2012b). Service quality precautions of travel agents on receiving mainland tourist to visit Taiwan (In Chinese) http://admin.taiwan.net.tw/law/law_d.aspx?no=130\&d=464

Truong, T. H., \& King B. (2009). An Evaluation of Satisfaction levels amongst Chinese Tourists in Vietnam. Journal of International Tourism Research, 11(6), 521-535.

Uren, J. (2009). The Chinese outbound travel market: Part 1. http://www.insights.org.uk/articleitem.aspx?title=The\%20Chinese\%20Outbound\%20Tra vel\% 20Market:\%20Part\%201

Wong, J., \& Law R. (2003). Difference in shopping satisfaction levels: a study of tourists in Hong Kong. Tourism Management, 24(4), 401-410.

World Tourism Organization. (2011). UNWTO Tourism Highlights, 2011 Edition. Madrid, Spain: UNWTO.

World Tourism Organization and European Travel Commission. (2008). The Chinese outbound travel market with special insight into the image of Europe as a destination. Madrid, Spain: World Tourism Organization and the European Travel Commission.

Yu, L., \& Goulden, M. (2006). A comparative analysis of international tourists' satisfaction in Mongolia. Tourism Management, 27(6), 1331-1342.

Zhang, G., Song, R. \& Liu, D. (2010). Annual Report China Outbound Tourism Development 2009/2010 Beijing, China: Profil Verlag.

Zhang, H., Chong, K. \& Ap, J. (1999). An analysis of tourism policy development in modern China. Tourism Management, 20(4), 471-485. 